Michel Girard MD MHPE FRCPC

\title{
Assessment of behavioural objectives in anaesthesia resident training
}

Residency training must be based on a comprehensive curriculum. Educators use the term behavioural objectives to represent educational objectives stated as behaviours that must be accomplished by the students. Educational objectives represent an important part of the curriculum content. However, curriculum content, as defined in large academic departments, has often been described as irrelevant for practitioners outside these large centres. Behavioural objectives drawn for the year of internal medicine, the fourth year of a five-year specialty programme in anaesthesia, were evaluated for their clinical relevance for anaesthetists in clinical practice outside cities where teaching programmes are found in the province of Québec. A questionnaire based on 288 objectives, using a rating scale, was used to compare the opinions of the members of the Education Committee (6) and outside practitioners (24). There were no significant differences between the mean ratings of the two groups of raters on ten of the 14 groups of objectives. A concordance of opinion was also present when there was disagreement with the importance of certain objectives. There was disagreement with only one group (VIII) of objectives on 14. Within this group there was agreement with the clinically oriented objectives and disagreement with the laboratory oriented objectives. Objectives that were related to the acute aspects of illness were rated higher than those related to their chronic aspects. The outside practitioners made 81 suggestions or comments about the abjectives.

Le contenu pédagogique de la résidence doit être basé sur un curriculum approprié. Des objectifs décrivant des comportements à atteindre sont une partie importante du curriculum.

\section{Key words}

EDUCATION: residents.

From the Department of Anaesthesia, Maisonneuve-Rosemont Hospital and University of Montreal, Montreal, Quebec.

Address correspondence to: Dr. Michel Girard, Department of Anaesthesia, Maisonneuve-Rosemont Hospital, 5415 boul. de l'Assomption, Montreal, Quebec, H1T 2M4.

Supported in part by the McLaughlin Foundation fellowship programme.

Accepted for publication 2nd February, 1992.
Cependant des objectifs pédagogiques définis dans des milieux universitaires ont souvent été décriés comment n'étant pas appropriés pour la pratique à l'extérieur de ces milieux. Des objectifs pédagogiques, décrits en termes de comportements et faits pour l'année de médecine interne, la quatrième de cinq années de résidence en anesthésie, ont été évalués en fonction de leur pertinence pour des anesthésistes ayant une activité clinique à l'extérieur des centres urbains où se trouve une faculté de médecine au Québec. Un questionnaire basé sur 288 objectifs, et utilisant une échelle de mesure, fut utilisé pour comparer l'opinion des membres du comité pédagogique (6) avec celle $d$ 'anesthésistes oeuvrant en périphérie (24). L'accord entre les deux groupes est grand. L'opinion des deux groupes concorde même lorsqu'ils sont en désaccord avec la pertinence de certains objectifs. On a trouvé une divergence d'opinion entre les deux groupes portant sur une seule série (VIII) d'objectifs sur quatorze. Dans cette série la différence d'opinion portait sur les objectifs orientés vers le laboratoire alors que les objectifs cliniques étaient évalués de façon semblable. Les objectifs reliés aux aspects aigus des maladies étaient mieux évalués que ceux portant sur leurs aspects chroniques. Le groupe d'experts externes a fait 81 suggestions ou commentaires portant sur les objectifs.

Medical education has been criticized for not providing education that is relevant to the practice of future physicians. Training takes place in large hospitals where the patients are often afflicted with complex or rare problems requiring teams of consultants to try to define and solve their problems. ${ }^{1}$ This phenomenon is compounded by the lack of emphasis on more common illness, as exemplified by Hodgkin who stated that there is "a nearly perfect inverse relationship between the amount of time or emphasis placed on a particular problem during the phases of medical training and the occurrence of that disease in general practice."2 Reuben described what he calls the residency-practice training mismatch. It is the rule, rather than the exception, that physicians in training will go on to work in settings quite different from the ones in which they were trained. As opposed to some primary care specialties, Reuben believed that anaesthesia residents 
"might experience little change on the completion of training."3 While this might be true of standard operating room practice, there is no evidence that the focus of internal medicine training in our programmes is adequate. An important step in designing a training programme is the elaboration of training objectives. One way to avoid the training practice mismatch is to have practitioners evaluate the relevance of the objectives.

The purpose of this study was to determine whether the objectives developed by the Education Committee of our department were considered by anaesthetists in primary care hospitals to be relevant to clinical practice.

\section{Methods}

A list of rotations for which objectives were most needed was determined by the Education Committee members, based on the Royal College of Physicians and Surgeons of Canada standards of training, their professionnal experience and the list of rotations most often asked for by the residents when planning their year of internal medicine. This list consisted of six different rotations: critical care medicine, haematology, cardiology, respiratory medicine, nephrology and endocrinology. A set of objectives was then drafted for each of these rotations. The final document was approved by the Education Committee and contained 288 objectives divided among the six headings, the last four were subdivided into three subheadings: preoperative evaluation, acute aspects and chronic aspects. Twelve subheadings were defined for critical care: cardiology, respiratory medicine, nephrology, endocrinology, haematology, multiple system organ failure (MSOF), hydroelectrolytic and nutritional needs, infectious syndromes, nervous system, psychiatry, patient transportation and trauma.

A questionnaire was constructed from the document listing the objectives. A graphic rating scale modified from Spivey $^{4}$ (Figure) and inserted after each objective was used to obtain the Education Committee members' and outside practitioners' rating of the relevance of each objective. A space dedicated for suggestions and comments was placed at the bottom of each page of the questionnaire. Practitioners were not asked to write objectives but simply to state if a topic should be added. Only one question was used to evaluate the duplicated objectives. The questionnaire was a 116 page document listing 239 questions.

The questionnaire was given to the members of the Education Committee and sent to 25 practitioners who had had at least nine months of clinical practice in anaesthesia in a non-teaching hospital and had received specialty certification within the last twelve years. These nonteaching hospitals were outside Montréal, Sherbrooke and Québec City. All former residents of the anaesthesia

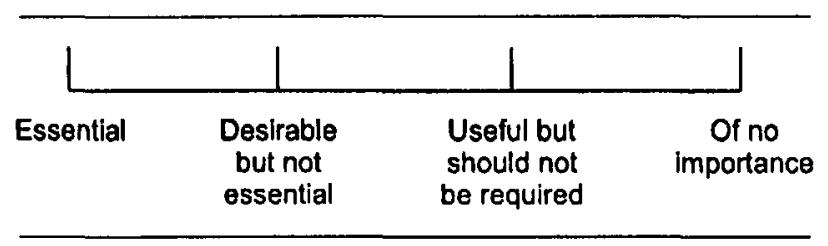

FIGURE Rating scale from Spivey, "essential" is given the value of 4 while "of no importance" corresponds to 1 .

programme of the Université de Montréal that could be reached over the telephone and who met the above criteria were asked to participate in the study. Twenty-four (73\%) former trainees out of a total of 34 eligible candidates and one graduate from another programme who worked with a group of our former graduates and volunteered for this study were reached. All agreed to participate in the study.

There were two data sources - committee members $(n=$ 6) and outside practitioners $(n=24)$. Jointly, these two groups are referred to as evaluators. Questions were grouped under 14 headings. The 14 groups and the number of objectives included in each one are as follows: Group I critical care medicine $(n=116)$; Group II: cardiology preoperative evaluation $(n=9)$; Group III: cardiology acute aspects ( $n=11$ ); Group IV: cardiology - chronic aspects $(n=27)$; Group V: respiratory medicine - preoperative evaluation $(n=3)$. Group VI: respiratory medicine - acute aspects ( $n=7)$; Group VII: respiratory medicine - chronic aspects $(n=12)$; Group VIII: haematology ( $n=13)$; Group IX: nephrology - preoperative evaluation $(n=4)$; Group $\mathrm{X}$ : nephrology - acute aspects $(n=6)$; Group XI: nephrology - chronic aspects $(n=10)$; Group XII: endocrinology - preoperative evaluation $(n=11)$; Group XIII: endocrinology - acute aspects $(n=14)$; Group XIV: endocrinology - chronic aspects $(n=29)$.

The following data were compared. First, the total number of answers rated under 3.0 and 3.3 by each group of evaluators. Second, the mean ratings for the 14 groups were computed by taking the mean of the ratings of each respondent for each group of questions and then averaging those results to get each of the two groups of evaluators' mean score. The means of the ratings and standard deviations for the two groups of evaluators, the 2-tailed $\mathrm{F}$ test for equality of variances and the 2-tailed t test for equality of means were tested. The full set of 288 objectives was used to make the statistical analysis. Third, after excluding critical care and haematology, the four remaining rotations (cardiology, respiratory medicine, nephrology and endocrinology) were divided into preoperative evaluation, acute aspects and chronic aspects. The objectives from these four rotations were regrouped under these three headings and a comparison of these three new groups was made to determine if the nature of the task to be accom- 
TABLE I Number of objectives considered less important by raters

\begin{tabular}{lcc}
\hline Groups of raters & Total of & 239 Items \\
\hline Mean scores & $<3.0$ & $<3.3$ \\
Education committee $(n=6)$ & 8 & 32 \\
Outside practitioners $(n=24)$ & 18 & 53 \\
\hline
\end{tabular}

TABLE II Mean scores and statistical comparison of the answers of the two groups of evaluators

\begin{tabular}{lcl}
\hline Groups & $\begin{array}{l}\text { Mean score } \\
\text { Education } \\
\text { Committee } \\
(n=6)\end{array}$ & $\begin{array}{l}\text { Mean score } \\
\text { outside } \\
\text { practitioners } \\
(n=24)\end{array}$ \\
\hline Group II & $3.9 \pm 0.08$ & $3.73 \pm 0.36$ \\
Group VIII & $3.5 \pm 0.18$ & $3.06 \pm 0.39$ \\
Group IX & $3.91 \pm 0.12$ & $3.63 \pm 0.34$ \\
Group XII & $3.95 \pm 0.07$ & $3.7 \pm 0.41$ \\
\hline
\end{tabular}

$P \leq 0.05$

plished (more or less acute care) rather than the type of medical sub-specialty concerned (e.g., cardiology, respiratory medicine, nephrology or endocrinology) was a source of disagreement between the two groups of evaluators. Last, the suggestions provided by the outside practitioners will be described and classified.

The value of $P \leq 0.05$ was used as the cutoff value for statistical significance.

\section{Results}

Twenty-four questionnaires, out of 25 , were returned to the investigator. Of these, 16 contained a total of 86 comments and/or suggestions.

\section{Results of the ratings}

Table I gives the number of items rated below 3.0 and below 3.3, out of the 239 items in the questionnaire, by each of the two groups of evaluators. The two values are given since 3.3 is often given as a "clearly discernable break point" while 3.0 describes what is "Desirable but not essential." All studies available ${ }^{5,6}$ that use the Spivey rating scale use 3.3 as their cutoff value.

There were no differences among the mean ratings of the two groups of raters on ten of the 14 groups of objectives. These were Groups I, III, IV, V, VI, VII, X, XI, XIII and XIV. For these groups mean ratings for both groups of evaluators exceeded 3.3 except Group XIV (outside practitioners $=3.28$ ). The mean scores of the Education Committee ranged from 3.43 (Group XI) to 4.0 (Groups V and VI). In other words, none of the Education Committee members' mean ratings was below the 3.3 level whereas two of the outside practitioners' ratings did ( 3.0 for Group
TABLE III Pooled mean scores and comparison of the answers with regard to the type of clinical activity

\begin{tabular}{llll}
\hline & $\begin{array}{l}\text { Mean score } \\
\text { pre-op. } \\
\text { evaluation }\end{array}$ & $\begin{array}{l}\text { Mean score } \\
\text { acute } \\
\text { aspects }\end{array}$ & $\begin{array}{l}\text { Mean score } \\
\text { chronic } \\
\text { aspects }\end{array}$ \\
\hline $\begin{array}{l}\text { Pooled values of the } \\
30 \text { respondents }\end{array}$ & $3.77 \pm 0.25$ & $3.69 \pm 0.24$ & $3.38 \pm 0.37$ \\
\hline
\end{tabular}

$P \leq 0.05$

VIII and 3.28 for Group XIV). Their highest rating (3.98) was assigned to Group VI.

\section{Groups II, VIII, IX and XII}

There were four groups of objectives for which there were differences between the mean ratings of the Education Committee and the outside practitioners. These were Groups II (cardiology - preoperative evaluation), VIII (haematology), IX (nephrology - preoperative evaluation) and XII (endocrinology - acute aspects) (Table II).

For all four groups the Education Committee rated the objectives higher than did the outside practitioners. However, all of the ratings for Groups II, IX and XII were well above 3.3 indicating that both groups feel these objectives are important although not with quite the same emphasis.

For the Group VIII (haematology) objectives the outside practitioners disagreed with the teaching committee members on a number of items. These objectives can be subdivided into two groups, laboratory and clinical objectives.

Mean ratings for these two subsets of objectives were computed, and the means were compared using a twotailed $t$ test. The Education Committee rated the laboratory objectives higher $(2.67 \pm 0.47)$ than did the outside practitioners $(1.96 \pm 0.73)$ while the ratings of the clinical objectives were not significantly different $(3.87 \pm 0.16 \mathrm{vs}$ $3.55 \pm 0.37)$.

\section{Importance of the nature of the task}

The ratings of the Teaching Committee and the outside practitioners were pooled to evaluate the difference of the mean ratings of the three headings (Table III). There was a difference between preoperative evaluation and acute aspects $(P \leq 0.01)$, with the preoperative objectives rated higher. The difference between the preoperative and the chronic aspects was significantly different $(P \leq 0.000)$ as was the difference between the acute aspects mean and the chronic aspects mean $(P \leq 0.000)$ with the chronic aspects mean being lower in both cases.

Therefore, preoperative evaluation is rated higher than acute aspects which is rated above chronic aspects. The 
TABLE IV Examples of suggestions/comments made by practitioners, the number between parentheses indicates the number of times it was given

Ethics (15)

About objective \#1

- Interpersonal relations with consultants and health care personnel, nurses, etc. (3)

- Administrative aspects (2)

- Overtreatment

- Rules for admission (3)

- Legal responsibility of patients unable to give consent

- Setting up of a learning environment for all personnel

- Organ transplant policies relating to donors

- Correct procedures of transfer of care to nursing personnel

- Extensively burnt patient

- Add monitoring means to therapeutic means

Renal system (4)

Add to page \#24 (2):

- Physiologic effects of dialysis (2)

Add to objective \#57:

- Magnesium deficit

Add to objective \#61:

- Be more specific about cocaine

difference of the means between the first and second heading is smaller $(0.08)$ than the difference between the second and third headings (0.31).

\section{Outside practitioners' suggestions}

The 24 outside practitioners made 86 comments/suggestions. Duplications and suggestions of elements already presentin the text (usually because thesuggestion preceded the reading of the duplicated objective) were eliminated, leaving 81 suggestions. The 81 suggestions were related to the different groups in the following order of importance: intensive care: 73 comments or suggestions, cardiology: 4 , respiratory medicine: 1 , haematology: 2 and endocrinology: 1. They were directed towards suggesting topics that had been omitted in the document. Examples of suggestions and comments can be found in Table IV.

\section{Discussion}

There is no universal agreement on the use of behavioural objectives in medical education. Most authors seem to agree with the concept of behavioural objectives and opposition is mainly directed toward the use that medical educators make of them. Since the concept and the use of objectives are slowly being implanted in Canadian medical education and because our main accrediting body, the Royal College of Physicians and Surgeons of Canada, has asked for their utilization, it was felt that the restructuring of the curricular content had its best chance of success if behavioural objectives were used rather than a totally unfamiliar educational strategy.
When objectives are the product of a group, the literature tends to imply that all members of the group agree with the objectives. This agreement, however, has never been documented. To our knowledge, this is the first study where the opinions of the authors of the objectives are compared with those of external practitioners.

Only two studies using Spivey's rating scale can be compared with this investigation. The first work by Spivey was aimed at evaluating a curriculum in ophthalmology for medical students, the second, by Arsham, was used to define an internship curriculum. In each of the studies "a clear break of the distribution was found at the mean rating of 3.3." In Spivey's study 27 (61\%) of 44 objectives were rated below 3.3, while 64 (32\%) of 195 objectives were rated similarly in Arsham's work. ${ }^{5}$

The agreement in this study can be explained in different ways. All members of the two groups were anaesthetists, whereas in the studies mentioned above, the raters came from different fields of expertise to evaluate programme objectives. Although certain objectives were from their domain of medical expertise, the entire programme was not specifically directed towards training in their specialty. This may have resulted in the low agreement in some of these studies for two reasons. First, a lack of understanding of the background of a clinical setting in which someone from another medical group works may cause misconceptions regarding the knowledge that the students need. Second, competition among groups of physicians from different specialties may cause them to differ about what content is important for the other group.

Another element that may explain the results is the topic: the year of internal medicine. Medical problems are usually not the primary reason for consultation by patients, except in the critical care setting. A surgical procedure of limited extent can be complicated by concurrent medical illness which is not related to the surgical problem. In many instances this is more important for the outcome of surgery than the surgery. Anaesthetists practicing in nontertiary care hospitals are part of the final documentation/decision of the impact of the medical problem on the outcome of the proposed intervention or are confronted with a sudden and/or unexpected situation that warrants immediate action. Therefore, they need a broad knowledge regarding medical issues. These preoccupations might explain the generally high scores given to the objectives by the outside practitioners. An important source of bias could have been previous training using these objectives. However, the objectives were new and no evaluator had been exposed to them during training. The practitioners were not randomly selected because the size of the task might have resulted in a low response rate.

Group VIII (haematology) responses warrant some comments. Mean ratings were different $(P=0.01)$ between 
the two groups of raters (Table II). Disagreement with some of the objectives by the Education Committee as well as by the outside practitioners may be explained by the nature of these objectives. These are the only objectives that are not entirely clinical; some of them relate to laboratory medicine. This heading was divided into two general topics: coagulation (objectives \#203 to 208) and blood bank (objectives \#209 to 215). Each of these sections were composed of objectives of a clinical or laboratory nature. Ratings by the Education Committee members and by the outside practitioners depended largely on the nature of the task/knowledge to be acquired/tested. Laboratory tests which were to be performed by the student were rated low while knowledge of a more clinical nature was given a higher rating. These laboratory-oriented objectives were written with the belief that performing these analyses would allow students a better understanding of the mechanics underlying the physiological phenomena found in clinical practice. The question that arose from this general disagreement was whether respondents believed that these issues were unimportant or that the method (laboratory instead of clinical work) of attaining them was unnecessary or misunderstood. Canfield ${ }^{7}$ cautions that the purpose of objectives should be well understood by their users. The disagreement seen here could reflect the practitioners' misunderstanding of the final purpose of the laboratory objectives which is to allow a deeper understanding of the mechanism of coagulation and of the problems related to the haematological aspects of transfusion therapy.

The nature of the anaesthetists' work was well represented by the different ratings given to the objectives pertaining to preoperative evaluation, acute care and chronic aspects of the task. Preoperative evaluation and acute care are more often related to situations that call for immediate decisions and imply clear knowledge of the medical issues involved. Group XIV (endocrinology chronic aspects) was rated lower, probably because endocrinology is considered less of an acute care medical specialty. Even if some endocrine illnesses are acute medical emergencies, they are usually taken care of before surgery and rarely occur during anaesthesia.

One unexpected finding was the disagreement of the Education Committee members with a number of objectives (Table I). Of the 32 objectives rated below 3.3 by the Education Committee members, 24 come from Groups IV $(n=6)$, VII $(n=3), \mathrm{XI}(n=4)$ and XIV $(n=11)$. The main characteristic of these groups was that they represented the chronic aspects of their medical sub-specialties. Groups I, VIII and X were the other groups where items were rated below 3.3. Although no written evaluation of the document had been made before its publication, it had been extensively discussed. Explanations for this disagreement ranged from fatigue related to lengthy revision procedures to fear of negative peer opinion if one disagreed and challenged the usefulness of a body of knowledge proposed by another committee member. In the future, this issue will be bypassed by formal evaluation before publication of similar work.

Finally, the excellent return rate can be explained by the sense of ownership imparted upon outside practitioners through personal communication, the timeliness of the subject and because it originated from their former training programme.

\section{Acknowledgments}

I would like to thank my thesis committee - R. Foley, D. Juul and B. Barzansky and the members of the Department of Anaesthesia at Maisonneuve-Rosemont Hospital who allowed me time to attend each block of the programme. The writing and revision of the objectives was by the members of the Education Committee - R. Desjardins, $\mathbf{P}$ Limoges, E. Villeneuve, J. Maucotel, L. Roux, R. Laberge and $\mathrm{H}$. Germain. Finally, I am grateful to all anaesthetists, members of the Education Committee and the 24 practitioners who answered the questionnaire.

\section{References}

1 White KL, Williams TF, Greenberg BG. The ecology of medical care. N Engl J Med 1961; 18: 885-92.

2 Hodgkin $K$. Towards Earlier Diagnosis. Edinburgh: E\&S Livingston, Ltd., 1966.

3 Reuben $D B, M c C u e J D$, Gerbert $B$. The residency-practice training mismatch. Arch Intern Med 1988; 148 : 914-9.

4 Spivey $B E$. A technique to determine curriculum content. J Med Educ 1971; 46: 269-74.

5 Arsham GM, Good N. Determination of internship objectives. J Med Educ 1974; 49: 446-8.

6 Gjerde C, Sheehan TJ. The development of performance standards for medical students. Eval Health Prof 1980; 2 : 237-48.

7 Canfield AA. A rationale for performance objectives. Audiovisual Instruction 1968; February: 127-9. 